\title{
Estudo cinético da enzima catalase (E.C. 1.11.1.6) de extrato bruto de batata doce (Ipomoea batatas)
}

\author{
Kinetic study of catalase enzyme (E.C. 1.11.1.6) from crude extract of sweet potato (Ipomoea \\ batatas)
}

\author{
M. F. R. F. Belo ${ }^{1}$; A. L. F. Souza ${ }^{1 *}$ \\ ${ }^{I}$ Curso Técnico em Química/Laboratório de Bioquímica, Instituto Federal Catarinense, 89245-000, Araquari-SC, \\ Brasil
}

*andre.fachini@ifc-araquari.edu.br

(Recebido em 23 de outubro de 2015; aceito em 29 de abril de 2016)

\begin{abstract}
Este trabalho utilizou um extrato bruto de batata doce (Ipomoea batatas) para estudar o efeito da variação de alguns parâmetros cinéticos ( $\mathrm{pH}$, temperatura, concentração de enzima e substrato) sobre a atividade da enzima catalase (hidroperoxidase, E.C. 1.11.1.6). Esta enzima está presente na maioria dos organismos e serve para proteger a célula de espécies reativas de oxigênio, subproduto de algumas reações metabólicas e responsáveis pelo estresse oxidativo. Os resultados obtidos sugerem que a catalase de batata doce apresenta estabilidade e atividade catalítica máxima na faixa de $\mathrm{pH} 6,0-9,0$ e de temperatura $25-30{ }^{\circ} \mathrm{C}$, utilizandose para ensaios da variação de concentração de enzima e substrato $\mathrm{pH} 7,0$ e temperatura de $30{ }^{\circ} \mathrm{C}$. A catalase foi ensaiada quanto a variação da concentração de substrato de acordo com a cinética de MichaelisMenten, apresentando um valor aparente de velocidade máxima $\left(V_{\text {máx }}\right)$ de $0,31 \mathrm{~mol} / \mathrm{L} / \mathrm{min}$. e $K_{\mathrm{m}}$ aparente de $0,19 \mathrm{~mol} / \mathrm{L}$.

Palavras-chave: catalase, batata doce, cinética
\end{abstract}

This work used a crude extract from sweet potato (Ipomoea batatas) to study the effect of the variation of some kinetic parameters $(\mathrm{pH}$, temperature, enzyme concentration and substrate) on the activity of catalase enzyme (hydroperoxidase, EC 1.11.1.6). This enzyme is present in most organisms and serves to protect the cell from reactive oxygen species. It is a byproduct from some metabolic reactions and responsible for oxidative stress. The results suggest that the sweet potato catalase has stability and maximum catalytic activity in the $\mathrm{pH}$ range $6.0-9.0$ and temperature range $25-30^{\circ} \mathrm{C}$. We have used a $30^{\circ} \mathrm{C}$ temperature and $7.0 \mathrm{pH}$ values for the variation of substrate and enzyme concentration assays. Catalase was assayed for the variation of substrate concentration based on Michaelis-Menten kinetics, presenting an apparent magnitude of maximum velocity $\left(V_{\max }\right)$ of $0.31 \mathrm{~mol} / \mathrm{L} / \mathrm{min}$. and apparent $K_{\mathrm{m}}$ of $0.19 \mathrm{~mol} / \mathrm{L}$.

Keywords: catalase, sweet potato, kinetic

\section{INTRODUÇÃO}

Catalases (hidroperoxidases, E.C. 1.11.1.6) são enzimas presentes na maioria dos organismos aeróbicos e auxiliam a célula na detoxificação de espécies reativas de oxigênio. Estas enzimas atuam na catálise da conversão de peróxido de hidrogênio $\left(\mathrm{H}_{2} \mathrm{O}_{2}\right)$ em água e oxigênio [1].

Algumas reações do metabolismo de aminoácidos e lipídios levam à produção de radicais livres e $\mathrm{H}_{2} \mathrm{O}_{2}$, espécies químicas muito reativas, capazes de danificar a célula. Para contornar este problema, essas reações são segregadas em pequenas vesículas delimitadas por membrana, os peroxissomos, ou glioxissomos no caso de certas células de plantas. A enzima catalase está localizada nos principais sítios de produção de $\mathrm{H}_{2} \mathrm{O}_{2}$, como mitocôndria, citosol e cloroplasto (plantas) $[2,3]$.

Estruturalmente, existem três famílias de proteínas capazes de degradar $\mathrm{H}_{2} \mathrm{O}_{2}$. Duas delas são enzimas que contêm o grupo heme, as catalases típicas (monofuncional) e as catalase-peroxidases (bifuncional). As catalases típicas são as mais abundantes em eubactérias, arqueobactérias, protistas, fungos, plantas e animais, enquanto que as catalases-peroxidases não são encontradas em plantas e animais. O terceiro grupo compreende aquelas que possuem um centro binuclear de manganês no sítio ativo (Mn-catalases), ao invés de possuir o grupo heme. Apesar de ambas catalisarem a mesma reação, diferem na arquitetura do sítio ativo e no mecanismo da reação $[4,5$, 
6]. As catalases mais comuns são tetraméricas, possuindo quatro grupos heme. Algumas possuem o cofator $\mathrm{NAD}(\mathrm{P}) \mathrm{H}$ fortemente ligado à superfície da enzima [7].

$\mathrm{O}$ mecanismo de ação da catalase monofuncional inicia com a entrada $\mathrm{o}_{2} \mathrm{H}_{2} \mathrm{O}_{2}$ no sítio ativo da enzima, onde há a transferência de um dos átomos de hidrogênio do $\mathrm{H}_{2} \mathrm{O}_{2}$ (na forma de próton) a partir de um dos átomos de oxigênio para o outro, mediado por um resíduo de histidina e um de asparagina, polarizando e estendendo a ligação $\mathrm{O}-\mathrm{O}$. Esta ligação sofre então uma cisão heterolítica, formando uma molécula de água. $\mathrm{O}$ outro átomo de oxigênio, coordenado ao átomo de ferro do grupo heme, forma a espécie $\mathrm{Fe}(\mathrm{IV})=\mathrm{O}$. Em uma segunda etapa, $\mathrm{Fe}(\mathrm{IV})=\mathrm{O}$ reage com uma segunda molécula de $\mathrm{H}_{2} \mathrm{O}_{2}$, removendo um átomo de oxigênio, formando $\mathrm{O}_{2}$, com o ferro retornando ao estado de oxidação inicial da enzima, $\mathrm{Fe}(\mathrm{III})[1,5,8,9,10]$.

Durante a respiração celular, o oxigênio molecular $\left(\mathrm{O}_{2}\right)$ aceita quatro elétrons para produzir duas moléculas de água, porém, apenas é capaz de aceitar um elétron por vez. Este mecanismo leva a geração de espécies reativas de oxigênio (ROS), capazes de reagir com várias biomoléculas, alterando-as ou levando à inativação e consequente perda de atividade biológica $[11,12]$.

Os efeitos deletérios das ROS estão relacionados ao estresse oxidativo [13]. Em um organismo saudável, existem vários tipos de sistemas de defesa contra as ROS assim que são geradas. Entretanto, quando expostos a condições ambientais adversas como poluentes atmosféricos, fumaça de cigarro, radiação ultravioleta, produtos avançados de glicação em diabéticos, entre outros, o organismo é levado a uma situação de estresse oxidativo [13,14]. Danos oxidativos às células são considerados como fatores significativos para processos de carcinogênese e envelhecimento.

Estudos mostraram que a ingestão a longo prazo de extratos de fruto de mirtilo (Vaccinium myrtillus L.) e vitamina E complexada a zinco, cobre, selênio e ácidos graxos poli-insaturados do tipo $\omega$-3 diminuiu consideravelmente a oxidação proteica no citosol e em extratos mitocondriais de hepatócitos de ratos Wistar e OXYS (ratos transgênicos que envelhecem rapidamente e apresentam doenças geriátricas). Esta suplementação também resultou no aumento da atividade de catalase em mitocôndrias hepáticas de ratos OXYS [15].

Outro estudo revelou que a ingestão oral de extrato de broto de trigo, rico em substâncias antioxidantes e com forte atividade de catalase, reduziu ou retardou significativamente a catarata senil canina [16].

Além da função celular e dos possíveis efeitos da ingestão, são produzidas catalases microbianas a partir de processos fermentativos para serem utilizadas na indústria têxtil, e com grande potencial para utilização na produção de alimentos e produtos farmacêuticos [17]. Uma catalase recombinante de Corynebacterium glutamicum foi produzida industrialmente e utilizada para limpeza de lentes de contato. Esta catalase apresentou melhor desempenho e se mostrou mais segura em comparação à enzima bovina [18]. A catalase também se mostrou vantajosa quando utilizada para o tratamento de tecidos de algodão após o processo de clareamento com peróxido de hidrogênio, apresentando uma melhora significativa no tingimento destes tecidos com corante reativo bifuncional [19].

Nesse sentido, o objetivo deste trabalho foi obter um extrato bruto de enzima catalase a partir de batata doce (Ipomoea batatas), uma fonte natural e de fácil aquisição, e estudar o efeito da variação de alguns parâmetros cinéticos sobre a atividade catalítica de conversão de peróxido de hidrogênio em água e oxigênio.

\section{MATERIAL E MÉTODOS}

A sequência experimental adotada neste trabalho divide-se em duas etapas, i) obtenção do extrato bruto da enzima catalase a partir de batata doce (Ipomoea batatas), e ii) ensaios de cinética enzimática. Para os experimentos cinéticos, a concentração de $\mathrm{H}_{2} \mathrm{O}_{2}$ remanescente nos sistemas de reação foi determinada após 15 minutos de incubação nas condições ensaiadas. Assim, para os ensaios do efeito da temperatura, $\mathrm{pH}$ e concentração de enzima, quanto menor a concentração de $\mathrm{H}_{2} \mathrm{O}_{2}$ determinada, maior a atividade enzimática observada. Nos experimentos 
do efeito da concentração de substrato, determinou-se a diminuição na concentração de $\mathrm{H}_{2} \mathrm{O}_{2}$ ($d[\mathrm{~S}] / d \mathrm{t}$ ) em relação à concentração inicial como estimativa da atividade enzimática.

\subsection{Obtenção do extrato bruto de catalase}

Foi preparado um extrato da enzima catalase a partir de 146,82 $\mathrm{g}$ de tubérculo de batata doce (Ipomoea batatas) sem cascas. Estas batatas foram homogeneizadas em liquidificador com 100 $\mathrm{mL}$ de tampão fosfato de sódio $0,1 \mathrm{~mol} / \mathrm{L} \mathrm{pH} 7,0$ estéril. Todos os reagentes líquidos foram previamente esterilizados em autoclave a $121{ }^{\circ} \mathrm{C}, 1$ atm por 20 minutos e resfriados antes da utilização para evitar a ação de proteases e manter a estabilidade da catalase. A mistura foi filtrada em gaze e o filtrado foi centrifugado a $10.000 \times \mathrm{g}$ por 10 minutos a $5{ }^{\circ} \mathrm{C}$. Ao sobrenadante (extrato bruto de catalase) foi adicionado glicerol para uma concentração final de $50 \%(\mathrm{v} / \mathrm{v})$ e armazenado a $-7{ }^{\circ} \mathrm{C}$. A quantidade de proteína total no extrato bruto de enzima foi determinada pelo método descrito por BRADFORD (1976) [20], utilizando albumina de soro bovino como padrão.

\subsection{Ensaios cinéticos}

Os ensaios de atividade de catalase foram efetuados em tubos de ensaio de $15 \mathrm{~mL}$ contendo o

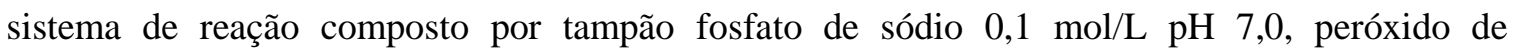
hidrogênio $\left(\mathrm{H}_{2} \mathrm{O}_{2}\right)$ e extrato bruto de catalase, totalizando um volume final de $3,2 \mathrm{~mL}$. Estes sistemas foram incubados por 15 minutos na temperatura apropriada para a condição testada.

A atividade da enzima foi determinada a partir da quantificação de $\mathrm{H}_{2} \mathrm{O}_{2}$ remanescente nos sistemas de reação por titulometria de oxirredução (permanganometria) [21], utilizando permanganato de potássio $0,02 \mathrm{~mol} / \mathrm{L}$ previamente padronizado com oxalato de sódio $0,05 \mathrm{~mol} / \mathrm{L}$. Imediatamente após a incubação das reações enzimáticas, foram adicionados $2 \mathrm{~mL}_{\text {de }} \mathrm{H}_{2} \mathrm{SO}_{4}$ 1:5 (v/v) aos sistemas de reação, seguido pela titulação.

Foi estudado o efeito dos parâmetros cinéticos temperatura, $\mathrm{pH}$, concentração de enzima e concentração de substrato sobre a atividade da enzima catalase. Para o estudo do efeito da temperatura, sistemas de reação contendo $\mathrm{H}_{2} \mathrm{O}_{2} 0,27 \mathrm{~mol} / \mathrm{L}$ e $200 \mu \mathrm{L}$ de extrato bruto de catalase (equivalente a $188 \mu \mathrm{g}$ de proteína total) foram incubados em temperaturas entre $8{ }^{\circ} \mathrm{C} \mathrm{e} 45^{\circ} \mathrm{C}$.

Para o estudo do efeito do $\mathrm{pH}$, foram preparadas soluções na faixa de $\mathrm{pH}$ 3-10 contendo $\mathrm{H}_{2} \mathrm{O}_{2}$ $0,27 \mathrm{~mol} / \mathrm{L}$ e $200 \mu \mathrm{L}$ de extrato bruto de catalase, seguido de incubação a $30^{\circ} \mathrm{C}$.

Para o estudo do efeito da concentração de enzima, foram testados sistemas de reação contendo $\mathrm{H}_{2} \mathrm{O}_{2} \quad 0,27 \mathrm{~mol} / \mathrm{L}$ e concentrações crescentes de extrato bruto de catalase (equivalentes a $47,94,141,188,235$ e $282 \mu \mathrm{g}$ de proteína total). Os sistemas foram incubados a $30^{\circ} \mathrm{C}$.

Para os ensaios do efeito da variação da concentração de substrato, foram preparados sistemas reacionais contendo $200 \mu \mathrm{L}$ de extrato bruto de enzima em tampão fosfato $0,1 \mathrm{~mol} / \mathrm{L} \mathrm{pH} \mathrm{7,0}$ contendo $\mathrm{H}_{2} \mathrm{O}_{2}$ nas concentrações $0,07,0,14,0,21,0,27,0,55$ e $1,38 \mathrm{~mol} / \mathrm{L}$ e incubados a $30{ }^{\circ} \mathrm{C}$. A partir destes ensaios foi possível estimar os valores de velocidade máxima $\left(V_{\text {máx }}\right)$ e constante de Michaelis-Menten $\left(K_{\mathrm{m}}\right)$.

\section{RESULTADOS E DISCUSSÃO}

O extrato bruto da enzima catalase, obtido a partir de batata doce, foi utilizado nos experimentos de avaliação do efeito da variação de parâmetros cinéticos sobre a atividade da enzima.

Para o estudo do efeito do $\mathrm{pH}$, foram testados sistemas de reação em uma faixa de $\mathrm{pH}$ de 3,0 a 10,0 (Figura 1A). Os resultados mostraram que a enzima apresenta atividade máxima na faixa de pH entre 6,0 e 9,0, com o valor médio de atividade máxima em pH 7,0.

Para o estudo do efeito da temperatura na atividade da catalase de batata doce, foram testados sistemas de reação incubados em temperaturas compreendidas entre $8{ }^{\circ} \mathrm{C}$ a $45^{\circ} \mathrm{C}$ (Figura 1B). A atividade máxima foi observada na faixa de temperatura entre $25{ }^{\circ} \mathrm{C}$ e $30{ }^{\circ} \mathrm{C}$. Apesar da diferença de atividade não ter sido muito grande dentro da faixa de temperatura analisada, optou-se em padronizar os experimentos a $30^{\circ} \mathrm{C}$. 
De maneira geral, as enzimas catalases apresentam grande estabilidade ao calor. Experimentos com catalases de diferentes fontes foram incubados a $65{ }^{\circ} \mathrm{C}$ e apresentaram uma diminuição de $50 \%$ na atividade em tempos bastante diferentes, que variaram de 0,1 a 720 minutos [1].

Um estudo analisou a catalase de folhas de batata doce, revelando atividade ótima na faixa de $\mathrm{pH}$ de 8,0 a 12,0 e pouco efeito na atividade enzimática na faixa de temperatura de 5 a $45^{\circ} \mathrm{C}$ [22]. Estes dados revelam que o comportamento da catalase do tubérculo estudada neste trabalho com relação ao efeito da temperatura corrobora com o estudo da catalase de folhas de batata doce, uma vez que o efeito da variação da temperatura não foi muito pronunciado. Com relação ao $\mathrm{pH}$, os resultados divergem, sugerindo diferenças entre as catalases obtidas a partir de diferentes partes da planta.

Catalase comercial e recombinante de $C$. glutamicum mostrou-se estável e com atividade máxima em uma larga faixa de temperatura $\left(20\right.$ e $\left.60{ }^{\circ} \mathrm{C}\right)$, com perda total de atividade em $70{ }^{\circ} \mathrm{C}$. A enzima catalase de fígado bovino apresentou atividade máxima entre 25 e $40{ }^{\circ} \mathrm{C}$, com atividade nula em torno de $65{ }^{\circ} \mathrm{C}$. Em relação ao efeito do $\mathrm{pH}$, catalases de $C$. glutamicum e de fígado bovino apresentaram atividade máxima em faixas de $\mathrm{pH}$ de 5,0-8,0 e 6,0-7,0, respectivamente [18]. Uma enzima catalase purificada de folhas de Phyllanthus reticulatus apresentou atividade máxima em $40{ }^{\circ} \mathrm{C}$ e pH 7,0 [23]. Catalase purificada parcialmente a partir de Malva sylvestris $\mathrm{L}$. apresentou pH ótimo de atividade em 7,5 nas formas livre e imobilizada em quitosana [24].

Os resultados do efeito da variação da temperatura e $\mathrm{pH}$ para a enzima catalase de batata doce estudada neste trabalho mostraram que esta enzima apresenta atividade máxima em faixas de temperatura e $\mathrm{pH}$ maiores que aquelas da enzima de fígado bovino, sugerindo maior potencial de aplicabilidade em processos industriais.

Baseado nos resultados, todos os demais experimentos foram realizados preparando-se sistemas de reação em tampão fosfato de sódio $0,1 \mathrm{~mol} / \mathrm{L} \mathrm{pH} \mathrm{7,0} \mathrm{e} \mathrm{incubados} \mathrm{a} 30^{\circ} \mathrm{C}$.

(A)

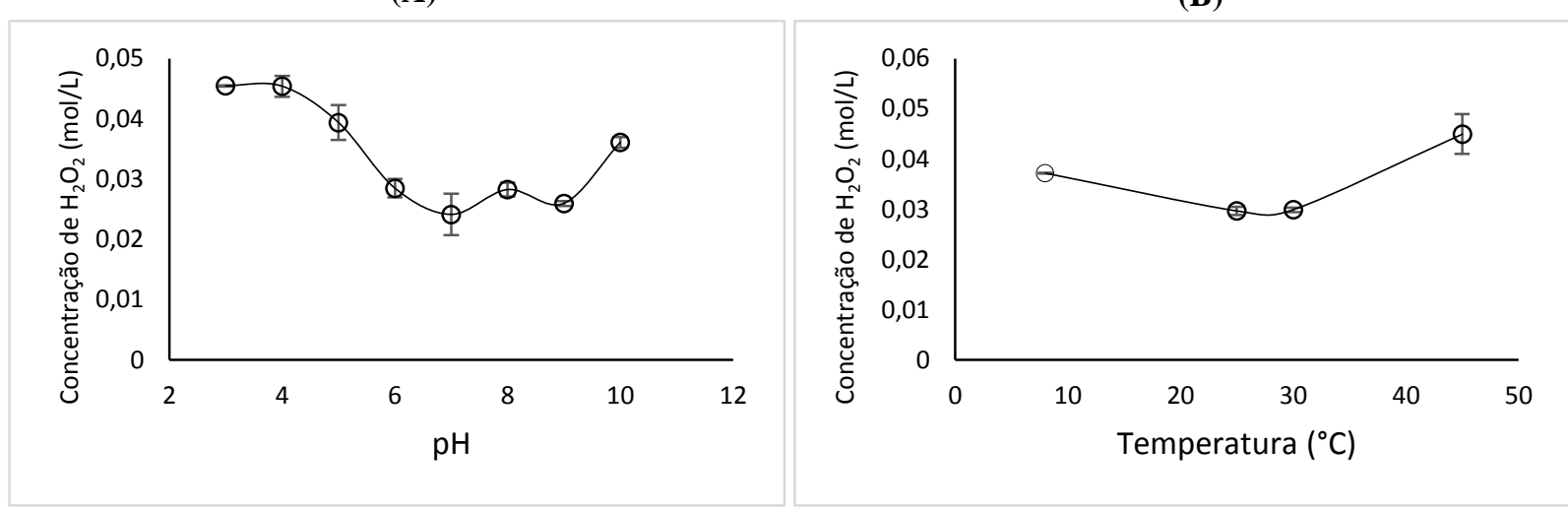

Figura 1: Efeito da variação do $\mathrm{pH}(\mathrm{A})$ e da temperatura (B) sobre a atividade da catalase de extrato bruto de batata doce (Ipomoea batatas). Em ambos os experimentos, os sistemas de reação foram incubados por 15 minutos. Os dados apresentados referem-se a um experimento representativo de três realizados em triplicada e independentemente.

Ensaios do efeito da concentração de enzima mostraram que a atividade máxima foi atingida quando se utilizou extrato de catalase contendo entre 188 e $235 \mu \mathrm{g}$ de proteína total (dados não mostrados). Para tanto, todos os sistemas de reação preparados neste trabalho utilizaram a quantidade de proteína total de $188 \mu \mathrm{g}$.

Para o estudo do efeito da concentração de substrato sobre a velocidade da reação catalisada pela enzima catalase deste trabalho considerou-se o esquema de BRIGS-HALDANE (1925) [25], onde: $\mathrm{E}+\mathrm{H}_{2} \mathrm{O}_{2} \leftrightarrows \mathrm{E}-\mathrm{H}_{2} \mathrm{O}_{2} \rightarrow \mathrm{E}+\mathrm{H}_{2} \mathrm{O}+\mathrm{O}_{2}$. Este esquema considera as reações de formação e dissociação do complexo enzima-substrato (ES) e a reação de decomposição deste complexo para a formação de produto.

Neste mecanismo, a enzima forma um complexo intermediário com o substrato $\left(\mathrm{H}_{2} \mathrm{O}_{2}\right)$ e esse complexo dá origem aos produtos $\left(\mathrm{H}_{2} \mathrm{O}\right.$ e $\left.\mathrm{O}_{2}\right)$, regenerando a enzima na sequência. Quando este esquema é aplicado à aproximação do estado estacionário, considera-se a concentração do 
complexo ES praticamente constante ao longo do tempo. A velocidade inicial $\left(v_{0}\right)$ medida reflete, neste caso, o estado estacionário, ainda que $v_{0}$ seja limitada aos tempos iniciais da reação. $\mathrm{Na}$ cinética de estado estacionário, a curva que expressa a relação entre a $v_{0}$ e a concentração de substrato tem a forma de uma hipérbole retangular para a maioria das enzimas, sendo expressa algebricamente pela equação de Michaelis-Menten [26].

A velocidade da reação é proporcional à concentração do complexo ES. Se a concentração de substrato é muito alta em relação à concentração de enzima, a enzima pode estar saturada de substrato e neste ponto o aumento da concentração de substrato não aumenta a concentração do complexo enzima-substrato, atingindo-se a velocidade máxima ( $\left.V_{\text {máx }}\right)$.

A velocidade da reação enzimática pode ser observada pela formação de produto $(\mathrm{P})$ ou pela diminuição da concentração de substrato, no início da mistura de enzima (E) e substrato (S). Assim, evita-se a interferência da variação da concentração de substrato [S], considerando-se que sua concentração é muito próxima do valor inicial. Desta forma, determina-se a velocidade inicial $\left(v_{0}\right)$ em que $[\mathrm{S}]$ é geralmente muito maior que $[\mathrm{E}][25,26]$.

Entretanto, as catalases são enzimas que não exibem cinética de Michaelis-Menten frente a qualquer concentração de substrato devido ao mecanismo da reação catalítica envolver duas etapas $[1,5,8,9,10]$. Todavia, em concentrações de substrato abaixo de $400 \mathrm{mmol} / \mathrm{L}$ muitas catalases exibem uma relação do tipo Michaelis-Menten entre a velocidade da reação e a concentração de substrato [1].

Desta forma, estudou-se o efeito da variação da $[\mathrm{S}]$ na $v_{0}$, quando a concentração de catalase $\mathrm{e}$ tempo de incubação são constantes (Figura 2A). Neste gráfico, a determinação do valor de $V_{\text {máx }}$ (velocidade máxima) e $K_{\mathrm{m}}$ ([S] correspondente a metade da $V_{\max }$ ) tornam-se imprecisos, necessitando-se linearizar este gráfico (Figura 2B), pelo método de Lineweaver-Burk, onde plotase o inverso da $v_{0}$ e o inverso da $[\mathrm{S}]$.

(A)

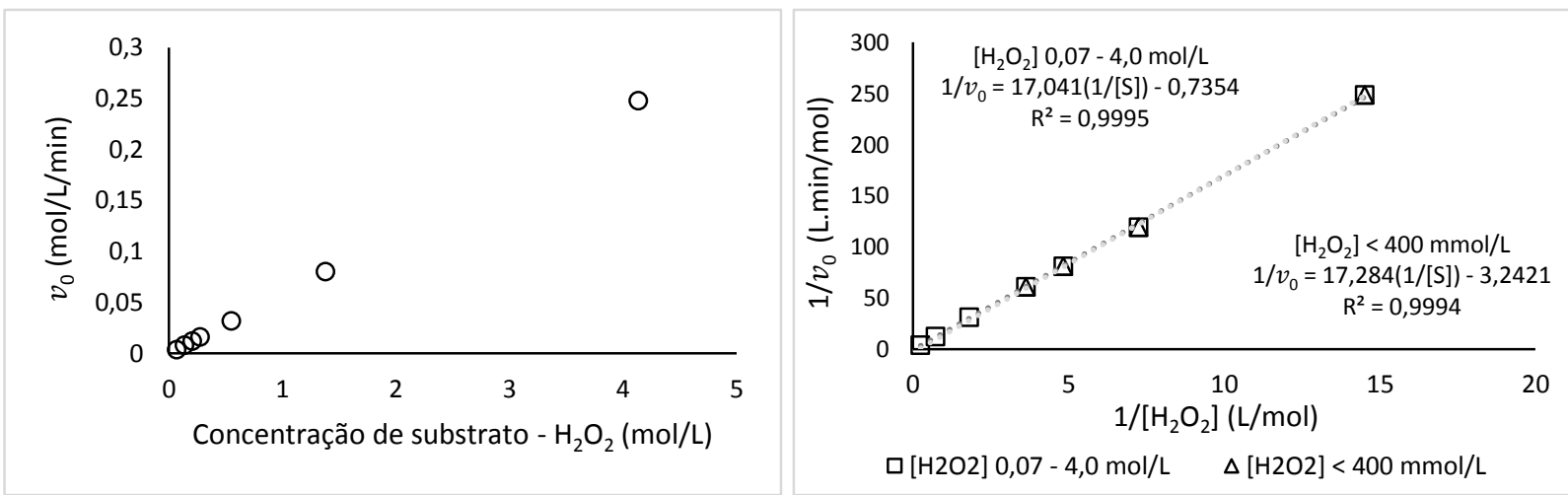

Figura 2: Gráfico de Michaelis-Menten (A) e linearização de Lineweaver-Burk (B). Para a linearização plotou-se $1 / v_{0} \times 1 /[S]$ para $[S]$ entre 0,07 e 4,0 mol/L $(\square)$ e $[S]<400 \mathrm{mmol} / \mathrm{L}(\Delta)$ como sugerido para muitas catalases. Ambos os gráficos representam um experimento de três realizados em triplicata e independentemente. Os desvios em torno da média não variaram além de $\pm 2,3 \%$.

No gráfico linear de Lineweaver-Burk, para concentrações de substrato inferiores a 400 $\mathrm{mmol} / \mathrm{L}$, a interseção da reta no eixo y $(1 /[\mathrm{S}]=0)$ equivale a $1 / V_{\text {máx }}$, determinando-se o valor aproximado de $V_{\text {máx }}$ aparente de $0,31 \mathrm{~mol} / \mathrm{L} / \mathrm{min}$. A interseção da reta no eixo x $\left(1 / v_{0}=0\right)$ equivale a $1 / K_{\mathrm{m}}$, encontrando-se o valor aproximado de $K_{\mathrm{m}}$ aparente de $0,19 \mathrm{~mol} / \mathrm{L}$.

$\mathrm{O}$ valor de $K_{m}$ é uma constante particular de cada enzima para um determinado substrato. Uma variação no valor de $K_{m}$ induzida por um ligante é uma maneira de regular a atividade enzimática. Pode-se ajustar as condições para se obter [S] muito superior ao valor de $K_{m}$ e se atingir a $V_{\text {máx }}$ da reação.

O estudo de 16 catalases de organismos pertencentes a vários clados filogenéticos apresentou valores de concentração de substrato que fornece metade da velocidade máxima ( $K_{\mathrm{m}}$ aparente) entre 38 e $600 \mathrm{mmol} / \mathrm{L}$, corroborando com o valor de $190 \mathrm{mmol} / \mathrm{L}$ para a catalase de batata doce estudada neste trabalho [1]. 
A enzima catalase purificada de folhas de $P$. reticulatus apresentou valor de $K_{\mathrm{m}}$ aparente de $0,74 \times 10^{-5} \mathrm{~mol} / \mathrm{L}$, sendo considerada uma boa fonte de enzima catalase e atividade antioxidante [23]. Ensaios cinéticos com a enzima catalase purificada parcialmente de M. sylvestris L. revelaram valores de $K_{\mathrm{m}}$ de $23,4 \mathrm{mmol} / \mathrm{L}$ para a enzima imobilizada em suporte de quitosana e $17,6 \mathrm{mmol} / \mathrm{L}$ para a enzima na forma livre [24].

É importante notar que a constante de Michaelis-Menten $\left(K_{\mathrm{m}}\right)$, assim como a velocidade máxima $\left(V_{\text {máx }}\right.$ ), são características da enzima e de seu substrato e independem da quantidade de enzima utilizada experimentalmente. Desta forma, as diferenças observadas na resposta à variação de parâmetros cinéticos entre as catalases de diferentes fontes podem ser explicadas pelas diferenças estruturais observadas entre essas enzimas, pelas características próprias de cada organismo, e consequente atividade diferenciada, bem como o grau de pureza da enzima utilizada nos ensaios experimentais.

\section{CONCLUSÃO}

O estudo da enzima catalase de extrato bruto de tubérculo batata doce (Ipomoea batatas) com relação a catálise da reação de conversão de peróxido de hidrogênio a água e gás oxigênio sugeriu atividade máxima da enzima em pH 7,0 e temperatura de $30{ }^{\circ} \mathrm{C}$. Ensaios da variação da concentração de substrato revelou velocidade máxima aparente de $0,31 \mathrm{~mol} / \mathrm{L} / \mathrm{min}$. e constante de Michaelis-Menten $\left(K_{\mathrm{m}}\right)$ aparente de $0,19 \mathrm{~mol} / \mathrm{L}$, determinados em concentrações de substrato inferiores a $400 \mathrm{mmol} / \mathrm{L}$, condição em que muitas catalases apresentam um comportamento do tipo Michaelis-Menten.

\section{AGRADECIMENTOS}

Este trabalho foi financiado pelo Instituto Federal Catarinense - Campus Araquari e Conselho Nacional de Pesquisa (CNPq), por meio de bolsa de iniciação científica (PIBIC-EM).

\section{REFERÊNCIAS BIBLIOGRÁFICAS}

1. Switala J, Loewen PC. Diversity of properties among catalases. Arch. Biochem. Biophys. 2002 401:145-154.

2. Del Río LA, Corpas FJ, Sandalio LM, Palma JM, Barroso JB. Plant peroxisomes, reactive oxygen metabolism and nitric oxide. IUBMB Life. 2003 55(2):71-81, doi: 10.1002/tbmb.718540875.

3. Sharma I, Ahmad P. Catalase: a versatile antioxidant in plants. Antioxidant Networks and Signaling. Academic Press:Waltham, 2014, p. 131-148, doi: 10.1016/B978-0-12-799963-0.000046.

4. Chelikania P, Fitab I, Loewen PC. Diversity of structures and properties among catalases. Cell. Mol. Life Sci. 2004 61:192-208.

5. Zamóchý M, Furtmuller PG, Obinger C. Evolution of catalases from bacteria to humans. Antioxid. Redox Signal. 2008 10(9):1527-1548, doi: 10.1089/ars.2008.2046.

6. Whittaker JW. Non-heme manganese catalase - the other catalase. Arch. Biochem. Biophys. 2012 525(2):111-20, doi: 10.1016/j.abb.2011.12.008.

7. Zamóchý M, Koller F. Understanding the structure and function of catalases: clues from molecular evolution and in vitro mutagenesis. Prog. Biophys. Mol. Biol. 1999 72(1):19-66, doi:10.1016/S0079-6107(98)00058-3.

8. Dounce AL. A proposed mechanism for the catalytic action of catalase. J. Theor. Biol. 1983 105(4):553-67.

9. Kato S, Ueno T, Fukuzumi S, Watanabe Y. Catalase reaction by myoglobin mutants and native catalase. J. Biol. Chem. 2004 279(50):52376-52381, doi:10.1074/jbc.M403532200.

10. Alfonso-Prieto M, Biarnés X, Vidossich P, Rovira C. The molecular mechanism of the catalase reaction. J. Am. Chem. Soc. 2009 131(33):11751-11761, doi: 10.1021/ja9018572.

11. Halliwell B, Gutteridge JMC. Oxygen-derived species and herbicide action. Physiol. Plant. 1984 $15: 21-24$. 
12. Scandalios JG, Guan L, Polidoros AN. Catalases in Plants: Gene Structure, Properties, Regulation, and Expression. Oxidative Stress and the Molecular Biology of Antioxidant Defenses. Cold Spring Harbor Liboratory Press: New York, 1994.

13. Sies, H. Biochemistry of Oxidative Stress. Angew. Chem. Internat. Ed. Eng. 1986 25:1058-71.

14. Devasagayam TPA, Tilak JC, Boloor KK, Sane KS, Ghaskadbi SS, Lele RD. Free radicals and antioxidants in human health: current status and future prospects. Japi. 2004 52:724-804.

15. Sinitsyna O, Krysanova Z, Ishchenko A, Dikalova AE, Stolyarov S, Kolosova N, Vasunina E, Nevinsky G. Age-associated changes in oxidative damage and the activity of antioxidant enzymes in rats with inherited overgeneration of free radicals. J. Cell. Mol. Med. 2006 10(1):206-215.

16. Marsili V, Calzuola I, Gianfranceschi GL. Nutritional relevance of wheat sprouts containing high levels of organic phosphates and antioxidant compounds. J. Clin. Gastroenterol. 2004 38(6):S1236.

17. Zhang D, Du G, Chen J. Fermentation production of microbial catalase and its application in textile industry. Sheng Wu Gong Cheng Xue Bao. 2010 26(11):1473-81.

18. Roche Diagnostics GmbH. Microbial catalase for personal healthcare and industrial applications. 2010.

19. Amorim AM, Gasques MFG, Andreaus J, Scharf, M. The application of catalase for the elimination of hydrogen peroxide residues after bleaching of cotton fabrics. An. Acad. Bras. Cienc. 2002 74(3):433-436.

20. Bradford MM. A rapid and sensitive method for the quantification of microgram quantities of protein utilizing the principle of protein-dye binding. Anal. Biochem. 1976 72:248-254, doi:10.1016/0003-2697(76)90527-3.

21. Owlweiler OA. Química analítica quantitativa. Rio de Janeiro: Livros Técnicos e Científicos, 1974.

22. Chen HJ, Afiyanti M, Huang GJ, Huang SS, Lin YH. Characterization of a leaf-type catalase in sweet potato (Ipomoea batatas Lam. (L.)). Bot. Stud. 2011 52:417-426.

23. Beulah K, Ramana T. Purification, properties and kinetic studies of catalase from Phyllanthus reticulatus. Int. J. Pharm. Chem. Biol. Sci. 2013 3(3):940-948.

24. Arabaci G, Usluoglu A. Catalytic Properties and Immobilization Studies of Catalase from Malva sylvestris L. J. Chem. 2013 2013:6p.

25. Briggs GE, Haldane JBS. A note on the kinetics of enzyme action. Biochem. J. 1925 19(2):338-9.

26. Johnson KA, Goody RS. The original Michaelis constant: translation on the 1913 MichaelisMenten paper. Biochem. 2011 50(39):8264-8269, doi: 10.1021/bi201284u. 